\title{
ADAÇAYI EKSTRAKTLARININ FARKLI YÖNTEMLER İLE KONSANTRASYONUNUN MATEMATİKSEL MODELLENMESİ VE KALİTE ÖZELLİKLERİNIN ARAŞTIRILMASI
}

\section{Cüneyt Dinçer*}

Akdeniz Üniversitesi Gıda Güvenliği ve Tarımsal Araștırmalar Merkezi, 07058, Antalya, Türkiye Akdeniz Üniversitesi Finike Meslek Yüksekokulu Gıda İşleme Bölümü, 07740, Antalya, Türkiye

Geliş / Received: 29.04.2020; Kabul / Accepted: 14.07.2020; Online bask1 / Published online: 04.08.2020

Dinçer, C. (2020). Adaçayı ekstraktlarının farklı yöntemler ile konsantrasyonunun matematiksel modellenmesi ve kalite özelliklerinin araştırılması. GIDA (2020) 45(4)736-747 doi: 10.15237/gida. GD20058.

Dinçer, C. (2020). Mathematical modeling of concentration of sage extract by different methods and investigation of quality properties. GIDA (2020) 45(4)736-747 doi: 10.15237/gida.GD20058.

ÖZ

Bu çalısmada adaçayı ekstraktlarının konsantrasyonunun modellenmesi ve konsantrasyon işleminin adaçayı ekstraktlarının kalite özellikleri üzerine etkisi araştırılmıştır. Bu amaçla uygulamalar termal vakum konsantrasyon $\left(75,80\right.$ ve $85^{\circ} \mathrm{C}, 250$ mbar basinç) ve mikrodalga vakum konsantrasyon (180, 300, ve 450W, 250 mbar basınç) olmak üzere iki farklı konsantrasyon sisteminde gerçekleştirilmiştir. Hedeflenen $40^{\circ} \mathrm{Bx}$ konsantrasyon seviyesine en kisa sürede 450 W'ta gerçekleştirilen mikrodalga vakum konsantrasyon uygulamasıyla ulaşılmıştır. Örneklerin konsantrasyon kinetiğinin modellenmesinde 13 farklı model kullanılmıştr. Termal yöntem ile konsantre edilen adaçayı ömekleriyle en iyi uyumu Modifiye Henderson ve Pabis modeli gösterirken, mikrodalga yöntemiyle konsantre edilen örnekler için en iyi uyum gösteren model Midilli olmuştur. Konsantre edilen örneklerin fizikokimyasal özelliklerinde genel olarak önemli değişimler gözlenmemiştir.

Anahtar kelimeler: Adaçayı, Salvia fruticosa, mikrodalga vakum konsantrasyon, matematiksel modelleme.

\section{MATHEMATICAL MODELING OF CONCENTRATION OF SAGE EXTRACT BY DIFFERENT METHODS AND INVESTIGATION OF QUALITY PROPERTIES}

\begin{abstract}
In this study, the modeling of the concentration of sage extracts and the effect of concentration on the quality properties of sage extracts were investigated. For this purpose, applications were performed in two different concentration systems: thermal vacuum concentration $\left(75,80\right.$ and $85^{\circ} \mathrm{C}$, 250 mbar pressure) and microwave vacuum concentration (180, 300, and 450W, 250 mbar pressure). The desired $40{ }^{\circ} \mathrm{Bx}$ concentration level in the shortest time was reached by the microwave vacuum concentration application at $450 \mathrm{~W} .13$ different mathematical models were used to describe the concentration kinetics. While the best fit with the sage samples concentrated by thermal method was the Modified Henderson and Pabis model, the model that showed the best fit for the samples concentrated by the microwave method was Midilli. It was observed that there was no significant difference in the physicochemical properties of the concentrated samples.
\end{abstract}

Keywords: Sage, Salvia fruticosa, microwave vacuum concentration, mathematical modelling.

*Yazışmalardan sorumlu yazar / Corresponding author

(1): cdincer@akdeniz.edu.tr,

(ग): (+90) 24222720 57/2598

且: (+90) 2423106506

Cüneyt Dinçer; ORCID no: 0000-0002-9160-4242 


\section{GİRIŞ}

Yüzyıllardır tıbbi amaçlı olarak kullanılan bitkiler "doğaya dönüş" akımının yaşandığı günümüzde yeniden önemli hale gelmiştir. Özellikle son yıllarda yapılan çalışmalarla tıbbi ve aromatik bitkilerin içerdiği biyoaktif bileşenlerin sağlık açısından önemli faydaları olduğunun vurgulanması bu bitkilerin tüketimini ve değerini arttırmıştır. Tibbi ve aromatik bitkiler içerisinde önemli bir yeri olan Lamiaceae (Ballıbabagiller) familyası, ülkemizde en yüksek endemizm oranına sahip familyaların başında gelmesi bakımından ayr1 bir değere sahiptir (Arslan vd., 2000). Lamiaceae familyasının en önemli üyeleri arasında yer alan, ülkemizde adaçayı ismi ile bilinen Salvia cinsi bitkiler geleneksel olarak ilaç amaçlı kullanımının yanında, kozmetik, parfümeri ve kimya endüstrisinde de kullanılabilmektedir. Ayrıca bu bitkiler özellikle et yemeklerinde aroma verici baharat olarak ve bitki çayı olarak da yaygın şekilde tüketilmektedir (Tunalıer vd., 2002; Delamare vd., 2007; Yağcıŏglu, 2015; Gezek vd., 2019).

Salvia türleri farklı nitelikte dal, yaprak ve çiçeklere sahip tek veya çok yıllık ve $50-100 \mathrm{~cm}$ arasında boylanabilen bitkilerdir (Davis, 1982). Bu bitki türleri, rüzgardan korunan, sicak ve güneşli, eğimli araziler üzerinde baskın olarak bulunur. Kış soğuklanına ve kuraklığa dayanıklı olan bu türler özellikle kireç içeriği bakımından zengin topraklarda iyi gelişir (Baydar, 2005). Latince kökenli bir kelime olan Salvia "iyileştirmek" veya "tedavi etmek" anlamlarını taşımaktadır. Kökeni ve yayılış alanı Akdeniz çevresi olan Salvia cinsinin en iyi bilinen türü ise tbbi adaçayı olarak da tanınan Salvia officinalis'tir (Davis, 1982; Tepe, 2002; Baydar, 2005). Ancak S. officinalis ülkemizde doğal olarak yetişmemekte, kültür koşullarında yetiştirilmektedir. Türkiye'de yaygın olarak bulunan ve ticari öneme sahip Salvia türlerinin başında ise Salvia fruticosa (sinonim S. triloba) gelmektedir (Baser, 2002; Baydar, 2005). S. fruticosa'nın önemli miktarda fenolikler ve terpenoidler gibi biyoaktif bileşenler içerdiği, antienflamatuar, antimikrobiyal ve antioksidan aktivitelerinin de çoğunlukla rosmarinik asit (fenolik) ve 1,8-sineol (terpenoid) ile ilişkili olduğu rapor edilmektedir (El-Sayed vd., 2001; Delamare vd., 2007; Şahin-Nadeem vd., 2013).

Geleneksel olarak, adaçayı yaprakları 3-5 dakika boyunca sıcak kaynamış suda demlenerek bitkisel çay olarak kullanılır. Son yıllarda ögütülmüşs adaçayı süzen poşetler içeresinde de yaygın olarak tüketilmektedir. Ancak bu yöntemlerde ekstraksiyonun etkin bir şekilde gerçekleştirilememesi, atık problemi ve bu işlemlerin pratik olmaması nedeniyle, yenilikçi ekstraksiyon yöntemlerinin yanı sıra ekstraktların konsantrasyonu ve instant bitki çayı üretim çalışmaları da önem kazanmıştır (Torun vd., 2014; Şahin-Nadeem vd., 2013). Bitki çaylarının istenen amaca uygun olarak çözünebilir formda kurutulması amaciyla, genel olarak ekstraksiyon, aroma ayırma, konsantrasyon ve kurutma gibi işlemler uygulanması gerekmektedir. Konsantrasyon işlemi instant içecek tozu üretiminde kritik bir aşamadır ve uygun maliyetli bir kurutma işlemi elde etmek için püskürtmeli kurutucudan önce kurutucuya verilecek siv1 konsantre edilir (Torun vd., 2014; Tontul ve Topuz, 2017).

Konsantrasyon işlemi genellikle termal yöntemler ile gerçekleştirilir. Ancak bu işlemde özellikle sürenin uzamasina bağlı olarak 1siya hassas bileșenlerce zengin ürünlerde önemli kayıplar, renk ve aromada istenmeyen değişiklikler meydana gelebilmektedir. $\mathrm{Bu}$ kayipların azaltılmasina yönelik olarak, termal yöntemle kombine olarak kullanılan sistemlerin yanı sıra alternatif konsantrasyon yöntemleri üzerine de çalışmalar yürütülmektedir. Bu kapsamda termal yönteme kıyasla daha kısa sürede, enerji ve kütle transferine imkân tanıyan mikrodalga vakum konsantrasyonu gibi yöntemler ön plana çıkmaktadır (Bozkir ve Baysal, 2017).

Mikrodalga ile 1sıtma tekniğinde gida maddesinde hacimsel 1sitma meydana gelmektedir. Hacimsel 1sıtma, g1daların mikrodalga enerjisini doğrudan ve dahili olarak emme ve 1siya dönüştürme yeteneği olarak ifade edilmektedir. Geleneksel 1sıtmada 1s1 genellikle yüzeyden iç kısma doğru aktarlırken, mikrodalga 1sıtmada ürün boyunca 1s1 üretilir. $\mathrm{Bu}$ nedenle, bir mikrodalga işleminde, 
1sitma oranlar1 genellikle geleneksel 1sitmadan daha yüksektir (Chandrasekaran vd., 2013).

Diğer taraftan mikrodalga 1sıtmanın sürekli modda uygulanması aşırı ve düzensiz 1sınmaya dolayısıyla ürünün kalite özelliklerinde istenmeyen baz1 değişikliklere neden olabilmektedir. Araştırmalar, aralıklı mikrodalga işleminin hem enerji verimliliğini hem de ürün kalitesini artırdığını göstermektedir (Kumar vd., 2016). Bu nedenle mikrodalga uygulamalar1 genelde kesikli uygulama modunda tercih edilmektedir. Mikrodalga 1sitmada dezavantajlardan biri de uygulamalarda elektromanyetik alan dağılımını ve etkisini izlemek veya kontrol etmek için yaygin ve basit bir yöntemin olmamasıdır (Vadivambal ve Jayas, 2007). Ancak, mikrodalga konsantrasyon işleminin modellenmesi, mikrodalga konsantrasyon işlemlerinin kontrolü ve optimizasyonunda fayda sağlayabilir. Ayrıca, matematiksel modellerin belirlenmesi mikrodalga konsantrasyon işlemlerinin verimliliğini artırabilir. $\mathrm{Bu}$ noktadan hareketle, bu çalışmanın amacı adaçayı ekstraktlarının mikrodalga ve termal yöntemler ile konsantrasyon karakteristiklerinin tanımlanmasında, matematiksel modellerin kullanılması ve ekstraktların fizikokimyasal özellikleri üzerine farklı konsantrasyon yöntem ve koşullarının etkilerinin değerlendirilmesidir.

\section{MATERYAL VE YÖNTEM}

\section{Materyal}

Çalışmada materyal olarak, yaklaşık $1.4^{\circ}$ Briks seviyesinde suda çözünür kuru madde içeriğine sahip adaçayı ekstraktı kullanılmıştır. Ekstraktı hazırlamak için Antalya'da faaliyet gösteren bir aktardan temin edilen adaçay1 (Salvia fruticosa) bitkisinin kurutulmuş yaprakları kullanılmıştır. Örnekler blendırda (Beko BKK-2155 Maxi El Blendırı, Türkiye) öğütüldükten sonra eleklerden (Retsch, Almanya) elenerek partikül büyüklüğ̈nün $0.5-1 \mathrm{~mm}$ arasında olmas1 sağlanmıştr. Ekstraksiyon işlemi için öğütülmüş numuneden alınan yaklaşık $6 \mathrm{~g}$ örnek $250 \mathrm{~mL}$ 'lik cam şişelere aktarılmış ardından, katı sıvı oranı 4/100 olacak şekilde üzerine (144 $\mathrm{mL})$ ekstraksiyon sıcaklığındaki $\left(80^{\circ} \mathrm{C}\right)$ distile su ilave edilmiştir. Ekstraksiyon çalkalamalı su banyosunda (Memmert WNE 29, SV 2945
Almanya), $80{ }^{\circ} \mathrm{C}$ 'de, 150 devir/dk çalkalama hızında ve yaklaşık $90 \mathrm{dk}$ süreyle gerçekleştirilmiştir. Ekstraksiyon sonunda elde edilen ekstraktlar kaba filtre kağıdından süzüldükten sonra denemelere kadar $+4{ }^{\circ} \mathrm{C}$ 'de muhafaza edilmiştir.

\section{Yöntem}

\section{Termal vakum konsantrasyon}

Termal vakum konsantrasyon işlemi rotary evaporatör (Heidolph Hei VAP Precision, Almanya) kullanılarak gerçekleştirilmiştir. $\mathrm{Bu}$ amaçla elde edilen ekstrakttan $\left(1.4^{\circ} \mathrm{Bx}\right)$ her bir deneme için $250 \mathrm{~mL}$, cam balon içerisine aktarılmıştır. Ardından cam balonun sisteme bağlantısı gerçekleştirilerek örneklerin rotary evaporatörün su banyosunda 75 (T 75), 80 (T 80) ve $85{ }^{\circ} \mathrm{C}$ (T 85) olmak üzere, üç farklı sıcaklıkta 75 devir/dk döndürme hızında, 250 mbar mutlak basınç değerinde yaklaşık 40 Bx'e kadar konsantrasyonu gerçekleştirilmiştir.

\section{Mikrodalga vakum konsantrasyon}

Mikrodalga vakum konsantrasyon işlemi, programlanabilir SAMSUNG ME86V mikrodalga firın (100-800W $2450 \mathrm{MHz})$ ile evaporatör (Heidolph Hei VAP Precision, Almanya) entegre edilerek gerçekleştirilmiştir. $\mathrm{Bu}$ amaçla her bir deneme için $250 \mathrm{~mL}$ ekstrakt evaporatörün cam balonuna aktarılmış ve $30 \mathrm{~cm}$ uzunluğunda sıcaklığa dayanıklı şilifli (29/32) bir cam boru ile mikrodalga firında açılan delikten evaporatöre entegre edilmiştir. Benzer sistemler nar (Yousefi vd., 2012) ve ananas sularının (Assawarachan ve Noomhorm, 2011) konsantrasyonlarında da kullanılmıştır. Örnekler (köpürme ve yanma gibi olumsuzlukların meydana gelmemesi için) ön denemeler ile belirlenen üç farklı güç seviyesinde (180 (MW 180, 8 sn açık 22 sn kapali), 300 (MW 300, 12 sn açık 18 sn kapali) ve 450 W (MW 450, 18 sn açık 12 sn kapalı)) ve 250 mbar mutlak basınç altında 40 'Bx'e kadar konsantre edilmiştir.

\section{Konsantrasyonun Modellenmesi}

Konsantrasyon prosesleri süresince ekstraktlardan düzenli aralıklarla (75 T ve MW 180 örneklerinde $20 \mathrm{dk}, 80 \mathrm{~T}$ ve MW 300 örneklerinde $10 \mathrm{dk}, 85 \mathrm{~T}$ ve MW 450 örneklerinde 
$7.5 \mathrm{dk})$ örnekleme yapılarak ${ }^{\circ} \mathrm{Bx}$ değerleri belirlenmiştir. Örnekleme yapilırken vakum sistemi durdurularak örnek alımı gerçekleştirilmiş ardından aynı şartlarda sistem yeniden çalıştırılmıştır. Adaçayı ekstraktlarının konsantrasyon değişiminin tanımlanmasında Çizelge 1'de verilen modeller kullanılmıştır.

Çizelge 1. Adaçayı ekstraktlarının konsantrasyonu için uygulanan matematiksel modeller Table 1. Mathematical models applied to concentration of sage extracts

\begin{tabular}{|c|c|c|}
\hline $\begin{array}{l}\text { Model adı } \\
\text { Model name }\end{array}$ & $\begin{array}{l}\text { Model eşitliği } \\
\text { Model equation }\end{array}$ & $\begin{array}{l}\text { Kaynak } \\
\text { Reference }\end{array}$ \\
\hline Lewis & $\mathrm{B}-\mathrm{B}_{0}=\exp (-\mathrm{k} \cdot \mathrm{t})$ & Goula vd., 2014 \\
\hline $\begin{array}{l}\text { Henderson ve Pabis } \\
\text { Henderson and Pabis }\end{array}$ & $\mathrm{B}-\mathrm{B}_{0}=\mathrm{a} \cdot \exp (-\mathrm{k} . \mathrm{t})$ & Goula vd., 2014 \\
\hline Page & $\mathrm{B}-\mathrm{B}_{0}=\exp \left(-\mathrm{kt}^{\mathrm{n}}\right)$ & Goula vd., 2014 \\
\hline $\begin{array}{l}\text { İki-terimli } \\
\text { Two-term }\end{array}$ & $B-B_{0}=a \cdot \exp \left(-k_{0} \cdot t\right)+b \cdot \exp \left(-k_{1} \cdot t\right)$ & Delgado vd., 2014 \\
\hline $\begin{array}{l}\text { İki-terimli üssel } \\
\text { Two-term exponential }\end{array}$ & $\mathrm{B}-\mathrm{B}_{0}=\mathrm{a} \cdot \exp (-\mathrm{k} \cdot \mathrm{t})+(1-\mathrm{a}) \cdot \exp (-\mathrm{k} \cdot \mathrm{a} \cdot \mathrm{t})$ & Delgado vd., 2014 \\
\hline $\begin{array}{l}\text { Logaritmik } \\
\text { Logarithmic }\end{array}$ & $\mathrm{B}-\mathrm{B}_{0}=\mathrm{a} \cdot \exp (-\mathrm{k} \cdot \mathrm{t})+\mathrm{c}$ & Delgado vd., 2014 \\
\hline $\begin{array}{l}\text { Wang ve Singh } \\
\text { Wang and Singh }\end{array}$ & $\mathrm{B}-\mathrm{B}_{0}=1+\mathrm{a} . \mathrm{t}+\mathrm{b} \cdot \mathrm{t}^{2}$ & Goula vd., 2014 \\
\hline $\begin{array}{l}\text { Modifiye Henderson ve Pabis } \\
\text { Modified Henderson and Pabis }\end{array}$ & $B-B_{0}=a \cdot \exp (-k t)+b \cdot \exp (-g \cdot t)+c \cdot \exp (-h t)$ & Delgado vd., 2014 \\
\hline Midilli & $\mathrm{B}-\mathrm{B}_{0}=\mathrm{a} \cdot \exp \left(-\mathrm{kt}^{\mathrm{n}}\right)+\mathrm{b} \cdot \mathrm{t}$ & Midilli vd., 2002 \\
\hline Verma & $\mathrm{B}-\mathrm{B}_{0}=\mathrm{a} \cdot \exp (-\mathrm{kt})+(1-\mathrm{a}) \cdot \exp (-\mathrm{g} \cdot \mathrm{t})$ & Swain vd., 2012 \\
\hline $\begin{array}{l}\text { Difüzyon yaklaşımı } \\
\text { Diffusion approach }\end{array}$ & $B-B_{0}=a \cdot \exp (-k t)+(1-a) \cdot \exp (-k \cdot b \cdot t)$ & Swain vd., 2012 \\
\hline $\begin{array}{l}\text { B-B } B_{0} \text { 'in kökü } \\
\text { Root of } B-B_{0}\end{array}$ & $B-B_{0}=(n+k \cdot t)^{2}$ & $\begin{array}{l}\text { Vega-Gálvez vd., } \\
2008\end{array}$ \\
\hline $\begin{array}{l}\text { Modifiye Page } \\
\text { Modified Page }\end{array}$ & $\mathrm{B}-\mathrm{B}_{0}=\exp \left(-(\mathrm{kt})^{\mathrm{n}}\right)$ & Delgado vd., 2014 \\
\hline
\end{tabular}

Tüm modellerdeki parametreler Sigma Plot 11.0 (Systat Software, Inc., San Jose, CA, A.B.D.) programı kullanılarak belirlenmiştir. Modellerin uygunluğu belirtme katsayısı (coefficient of determination, $\mathrm{R}^{2}$ ), azaltılmış kikare (reduced chisquare, $\chi 2$ ) ve hata kareler ortalamasının karekökü (Root mean square error, RMSE) ile değerlendirilmiştir. $\mathrm{Bu}$ üç parametre Assawarachan ve Noomhorm (2011)'in çalışmasında bildirdiği gibi aşağıdaki eşitliklerle hesaplanmıştır.

$\mathrm{R}^{2}=1-(\mathrm{RSS}) /(\mathrm{TSS})$

$$
\begin{aligned}
& \chi 2=\frac{\sum\left(\Delta \mathrm{B}_{\text {exp }, \mathrm{i}}-\Delta \mathrm{B}_{\text {pred }, \mathrm{i}}\right)^{2}}{\mathrm{~N}-\mathrm{n}_{\mathrm{p}}} \\
& R M S E=\sqrt{\frac{1}{N} \sum_{i=1}^{N}\left(\Delta B_{\text {exp }, i}-\Delta B_{\text {pred }, i}\right)^{2}}
\end{aligned}
$$

Burada,

RSS: Artık Kareler Toplamı

TSS: Ortalamadan Ayrllış Kareler Toplamı $\Delta B_{\text {exp,i }}$ ve $\Delta B_{\text {pred,i sirasiyla gözlenen ve tahmin }}$ edilen konsantrasyon değişimi ( $\left.{ }^{\circ} \mathrm{Bx}\right), \mathrm{N}$ gözlem sayıs1, $\mathrm{n}_{\mathrm{p}}$ modeldeki sabit sayısıdır. 
Yaklaşı $40{ }^{\circ} \mathrm{Bx}$ 'e konsantre edilen örnekler analizler öncesi başlangıç konsantrasyonu olan 1.4 ${ }^{\circ} \mathrm{Bx}$ 'e destile su ile seyreltilmiş ve analizler bu örneklerde gerçekleştirilmiştir.

\section{Suda çözünür kuru madde tayini (SÇKM)}

Örneklerin suda çözünebilir kuru madde miktarı refraktometre (PAL- $\alpha$ ATAGO, Tokyo, Japonya) ile oda sıcakliğında ölçülmüştür.

\section{pH ve İletkenlik ölçümü}

Örneklerin pH ve iletkenlik değerleri oda sıcaklığında dijital $\mathrm{pH}$ metre (Orion 4-Star $\mathrm{pH}$ meter, Thermo Scientific, ABD) ve iletkenlik ölçer (Mettler Toledo S230, Switzerland) kullanılarak ölçülmüştür.

\section{Renk analizi}

Örneklerin renk analizi Konica-Minolta CR-400 (Japonya) renk ölçer cihazı ve sıvı kabı kullanılarak yapilmıştır. Renk, L* (koyuluk-açıklık), a* (yeşillikkırmızılık), b* (mavilik-sarılık) renk parametreleri cinsinden ifade edilmiştir. Ayrıca Hue açısı (h) ve Chroma (C) değerleri aşağıdaki eşitlikler ile hesaplanmıştır.

$h^{\circ}=\frac{180}{\pi} \tan ^{-1}(b / a)$

$C=\sqrt{\left(a^{2}+b^{2}\right)}$

\section{Bulanıklık}

Örneklerdeki bulanıklık değeri ölçümü için örnek $95 \mathrm{~mm}$ yüksekliği ve $25 \mathrm{~mm}$ çapa sahip örnek kabına yerleştirilmiş ve türbidimetre (Hach 2100 $\mathrm{N}$ Turbidimeter, A.B.D.) kullanilarak NTU (Nepholometric Turbidity Unit) değeri cinsinden belirlenmiştir (Tajchakavit vd., 2001).

\section{Toplam Fenolik madde}

Toplam fenolik madde miktar1 spektrofotometrik yöntemle belirlenmiştir. Bu amaçla, $0.5 \mathrm{~mL}$ örnek üzerine sırasıyla $2.5 \mathrm{~mL}$ Folin-Ciocalteu çözeltisi (saf su ile 10 kat seyreltilmiş) ve (0.5 ile $2 \mathrm{dk}$ arasında bekleme süresinden sonra) $2 \mathrm{~mL} \% 7.5^{\prime} \mathrm{lik}$ $\mathrm{Na}_{2} \mathrm{CO}_{3}$ çözeltisi eklenmiştir. Elde edilen kanısım vorteksle karıştırıldıktan sonra $50^{\circ} \mathrm{C}$ 'deki su banyosunda $5 \mathrm{dk}$ bekletilmiştir. Daha sonra oda sicakllğına soğutularak spektrofotometrede
(Thermo Scientific Evoluation 160 UV-Vis, ABD) $760 \mathrm{~nm}$ dalga boyunda, okunmuştur. Elde edilen absorbans değerleri gallik asit çözeltileri ile oluşturulan kurve yardımıla mg gallik asit eşdeğeri (GAE)/L esktrakta dönüştürülmüştür (Skerget vd., 2005).

\section{İstatiksel analizler}

Araşturma tesadüf parselleri deneme desenine göre iki tekerrürlü olarak gerçekleştirilmiş analizler paralelli olarak yürütülmüştür. Ortalamalar varyans analizine tabi tutularak, önemli bulunan farklilkklar Duncan Çoklu Karşılaştırma Testi ile ortaya konulmuştur.

\section{SONUÇ VE TARTIŞMA}

\section{Adaçayı ekstraktlarının konsantrasyon kinetiği}

Adaçayı ekstraktlarının farklı konsantrasyon yöntemleri kullanılarak elde edilen konsantrasyon eğrileri Şekil 1'de sunulmuştur. Başlangiç seviyesi olan $1.4^{\circ} \mathrm{Bx}$ ten adaçayı ekstraktlarının $40{ }^{\circ} \mathrm{Bx}$ 'e konsantrasyonu için gerekli süre, T75, T80 ve T85 örnekleri için sırasıyla $137.5,72.5$ ve $50 \mathrm{dk}$ olarak belirlenirken, MW180, MW300 ve MW450 örnekleri için ise sırasıyla 156.5, $69.75 \mathrm{ve} 40.5 \mathrm{dk}$ olarak belirlenmiştir. Hedeflenen konsantrasyon değerine ulaşmak için gerekli sürenin sicaklık $\left(75^{\circ} \mathrm{C}\right.$ ten $85^{\circ} \mathrm{C}$ 'ye) ve mikrodalga gücü (180W'tan 450W'a) artışılla azaldığı görülmektedir.

Vakum prosesi çözeltilerin kaynama noktasının düşmesine buna bağlı olarak hedeflenen konsantrasyon seviyesine daha kısa sürede ulaşılmasına imkan tanımaktadır. Diğer taraftan konsantrasyon sürecinde, çözeltinin suda çözünür kuru madde artışına bağlı olarak kaynama noktası da yükselmektedir (Yousefi vd., 2012). Bununla birlikte çözeltinin kaynama noktasındaki artışın suda çözünür kuru madde artışı yanında konsantrasyon yöntemi ile de ilişkili olduğu; nitekim mikrodalga vakum yöntemiyle konsantre edilen nar suyu örneklerinin kaynama noktalarının geleneksel vakum yöntemiyle konsantre edilenlerden daha fazla olduğu bildirilmektedir (Yousefi vd., 2012). Ayrica bu farkin konsantrasyon aşamasının sonuna doğru daha belirgin olduğu ve bu olayın süper isınma olgusundan kaynaklandığı rapor edilmektedir. 


\section{Adaçayı ekstraktlarının konsantrasyonu \\ Concentration of sage extracts}
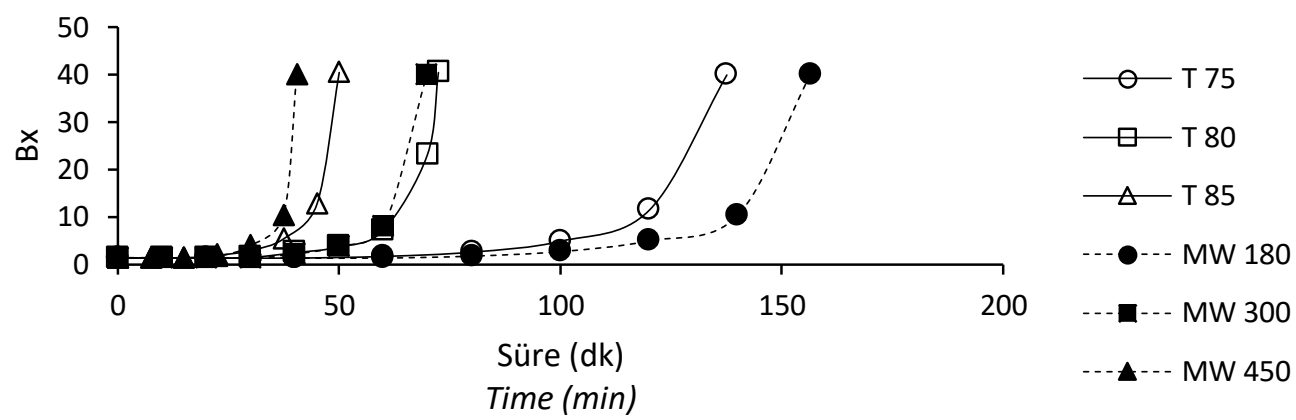

Șekil 1. Farklı yöntemler kullanılarak konsantre edilen adaçayı ekstraktların konsantrasyon kurvesi

Figure1. The concentration curves for sage extracts concentrated using the various techniques

Modellerin adaçayı ekstraktlarından elde edilen verilere (Çizelge 1) uygunluğunu belirlemek için hesaplanan regresyon katsayıları $\left(\mathrm{R}^{2}\right)$, azaltılmıs kikare $\left(\chi^{2}\right)$ ve hata kareler ortalamasi (RMSE) değerleri, Çizelge 2'de sunulmuştur. Termal yöntem ile konsantre edilen adaçayı örneklerinde, modellerin hesaplanan $\mathrm{R}^{2}$ değerleri 0.747 ile 1 arasında belirlenirken, $\chi^{2}$ ve RMSE değerleri ise sirasiyla 0.0161 ile 53.699 ve 0.1269 ile 7.328 arasında tespit edilmiştir. Mikrodalga yöntemiyle konsantre edilen örnekler için $\mathrm{R}^{2}, \chi^{2}$ ve RMSE değerleri ise sirasiyla 0.658 ile $0.9995,0.1628$ ile 83.0046 ve 0.4035 ile 9.1107 arasinda hesaplanmıştır.
Yüksek $\mathrm{R}^{2}$ ile düşük $\chi^{2}$ ve RMSE değerleri, modellerin verilere uygunluğunu ifade etmektedir. Bu doğrultuda termal yöntem ile konsantre edilen adaçayı örneklerine en iyi uyumu Modifiye Henderson ve Pabis modeli $\left(\mathrm{R}^{2} \geq 0.9999 ; \chi^{2} \leq\right.$ 0.0443 ; RMSE $\leq$ 0.2104) gösterirken, mikrodalga yöntemiyle konsantre edilen örnekler için en iyi uyum gösteren model Midilli $\left(\mathrm{R}^{2} \geq 0.9985 ; \chi^{2} \leq\right.$ 0.6066; RMSE $\leq$ 0.7789) olmuştur (Çizelge 2). Ayrıca Şekil 2 ve Şekil 3'te sunulan deneysel veriler ile tahmin edilen veriler karşılaştırıldığında, Modifiye Henderson ve Pabis ile Midilli modellerinin adaçayı ekstraktlarının konsantrasyon karakteristiklerini tahmin etmede oldukça bașarılı oldukları görülmektedir.

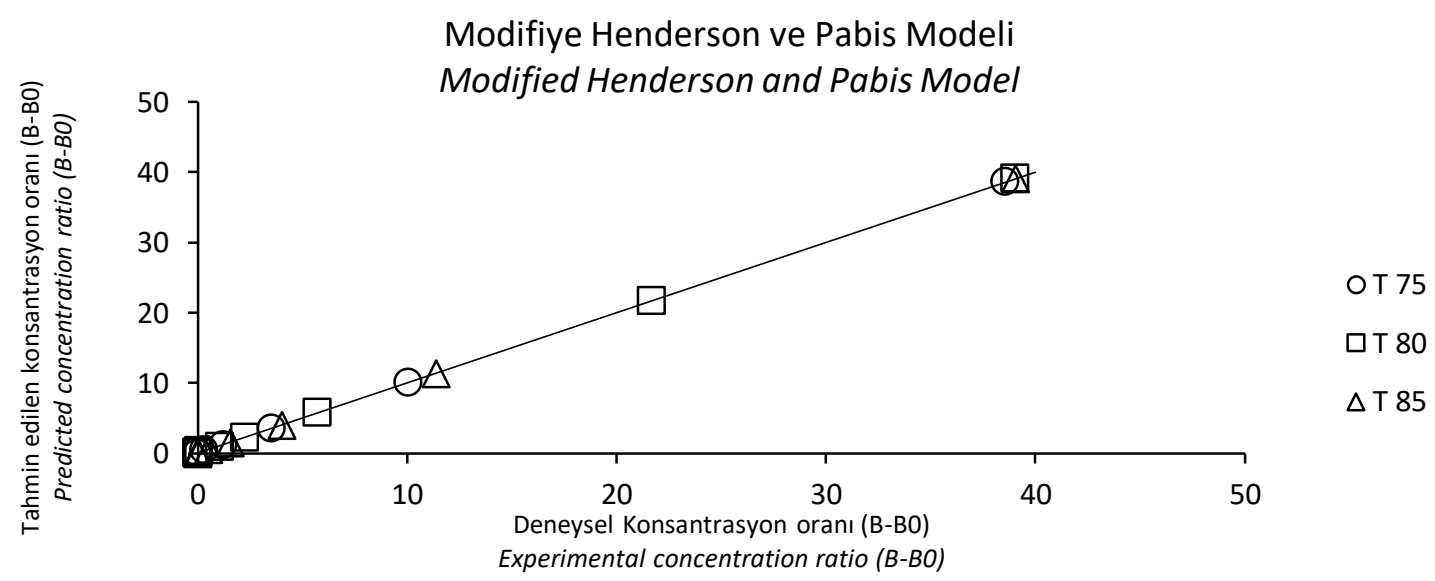

Şekil 2. Modifiye Henderson ve Pabis Modeli için adaçayı ekstraktlanındaki termal vakum konsantrasyonu değişiminin deneysel ve tahmin edilen değerleri.

Figure 2. Experimental and predicted values of thermal vacuum concentration change in sage extracts forModified Henderson and Pabis Model 


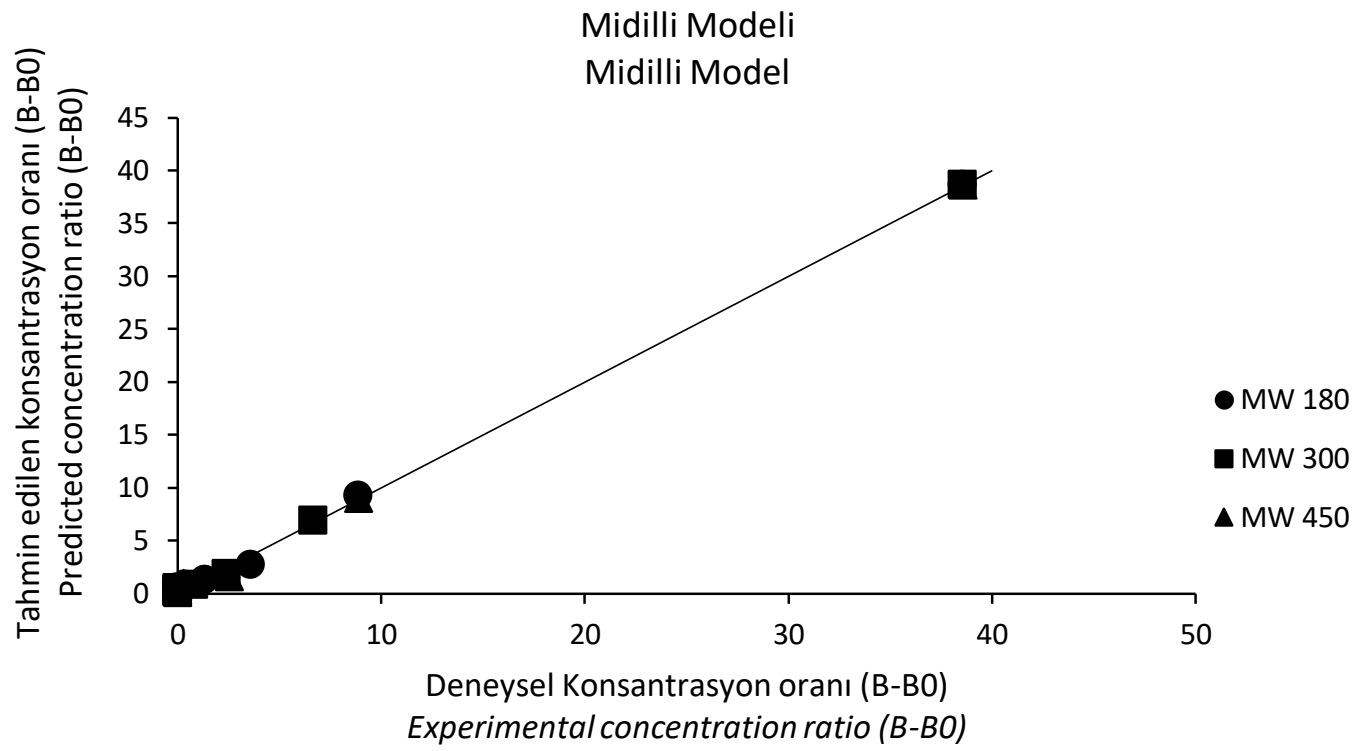

Şekil 3. Midilli Modeli için adaçayı ekstraktlarındaki mikrodalga vakum konsantrasyonu değişiminin deneysel ve tahmin edilen değerleri.

Figure 3. Experimental and predicted values of microwave vacuum concentration change in sage extracts for Midilli Model

Çizelge 2. Farklı yöntemler ile konsantre edilen adaçayı ekstraktlarının konsantrasyon verileri için kullanilan kinetik modellerin parametreleri

Table 2. Parameters of the kinetic models used to fit concentration data for sage extracts concentrated by various concentration techniques.

\begin{tabular}{llcccccc}
\hline $\begin{array}{l}\text { Matematiksel model } \\
\text { Mathematical model }\end{array}$ & Parametreler & \multicolumn{5}{c}{$\begin{array}{c}\text { Konsantrasyon metodu } \\
\text { Concentraion method }\end{array}$} \\
\hline & & \multicolumn{7}{c}{$\mathrm{T} 75$} & $\mathrm{~T} 80$ & $\mathrm{~T} 85$ & $\mathrm{MW} 180$ & MW 300 & MW 450 \\
\hline Lewis & $\mathrm{R}^{2}$ & 0.7637 & 0.77 & 0.747 & 0.6774 & 0.7062 & 0.658 \\
& $\chi^{2}$ & 41.9819 & 42.8731 & 46.0277 & 51.3596 & 52.3378 & 69.1705 \\
& $\mathrm{RMSE}$ & 6.4793 & 6.5478 & 6.7844 & 7.1666 & 7.2345 & 8.3169 \\
\hline Henderson ve Pabis & $\mathrm{R}^{2}$ & 0.9984 & 0.9907 & 0.9954 & 0.9961 & 0.9985 & 0.9955 \\
Henderson and Pabis & $\chi^{2}$ & 0.3375 & 1.988 & 0.9789 & 0.7035 & 0.3099 & 1.0869 \\
& $\mathrm{RMSE}$ & 0.5809 & 1.41 & 0.9894 & 0.8387 & 0.5567 & 1.0426 \\
\hline Page & $\mathrm{R}^{2}$ & 0.9966 & 0.9958 & 0.9969 & 0.9924 & 0.9963 & 0.9893 \\
& $\chi^{2}$ & 0.7067 & 0.9015 & 0.6633 & 1.3886 & 0.7697 & 2.5994 \\
& $\mathrm{RMSE}$ & 0.8407 & 0.9495 & 0.8144 & 1.1784 & 0.8773 & 1.6123 \\
\hline Íki-terimli & $\mathrm{R}^{2}$ & 0.9984 & 0.9907 & 0.9954 & 0.9961 & 0.9985 & 0.9955 \\
Two-term & $\chi^{2}$ & 0.5062 & 2.7832 & 1.4684 & 0.9849 & 0.4648 & 1.8116 \\
& $\mathrm{RMSE}$ & 0.7115 & 1.6683 & 1.2118 & 0.9924 & 0.6818 & 1.3459 \\
\hline İki-terimli üssel & $\mathrm{R}^{2}$ & 0.9967 & 0.9924 & 0.9957 & 0.9951 & 0.9964 & 0.9955 \\
Two-term exponential & $\chi^{2}$ & 0.6784 & 1.6249 & 0.9133 & 0.8861 & 0.7452 & 1.0835 \\
& $\mathrm{RMSE}$ & 0.8237 & 1.2747 & 0.9556 & 0.9413 & 0.8633 & 1.0409 \\
\hline Logaritmik & $\mathrm{R}^{2}$ & 0.9987 & 0.9926 & 0.9965 & 0.9969 & 0.9988 & 0.9965 \\
Logarithmic & $\chi^{2}$ & 0.3278 & 1.8274 & 0.8865 & 0.6676 & 0.3095 & 1.0554 \\
& $\mathrm{RMSE}$ & 0.5726 & 1.3518 & 0.9416 & 0.817 & 0.5564 & 1.0273 \\
\hline Wang ve Singh & $\mathrm{R}^{2}$ & 0.8244 & 0.8275 & 0.8018 & 0.7579 & 0.7835 & 0.7221 \\
Wang and Singh & $\chi^{2}$ & 36.4107 & 36.7478 & 42.0765 & 44.0582 & 45.0053 & 67.4573 \\
& $\mathrm{RMSE}$ & 6.0341 & 6.062 & 6.4866 & 6.6376 & 6.7086 & 8.2132 \\
\hline
\end{tabular}


Adaçayı ekstraktlarının konsantrasyonunun matematiksel modellenmesi

\begin{tabular}{llcccccc}
\hline Modifiye Henderson & $\mathrm{R}^{2}$ & 1 & 0.9999 & 1 & 0.9961 & 0.9985 & 0.9955 \\
ve Pabis & $\chi^{2}$ & 0.0161 & 0.0443 & 0.0244 & 1.6415 & 0.9297 & 5.4347 \\
$\begin{array}{l}\text { Modified Henderson and } \\
\text { Pabis }\end{array}$ & $\mathrm{RMSE}$ & 0.1269 & 0.2104 & 0.1561 & 1.2812 & 0.9642 & 2.3312 \\
\hline Midilli & & & & & & & \\
& $\mathrm{R}^{2}$ & 0.9995 & 0.9977 & 0.9989 & 0.9987 & 0.9995 & 0.9985 \\
& $\chi^{2}$ & 0.1503 & 0.6866 & 0.353 & 0.3237 & 0.1628 & 0.6066 \\
& $\mathrm{RMSE}$ & 0.3877 & 0.8286 & 0.5941 & 0.5689 & 0.4035 & 0.7789 \\
\hline Verma & $\mathrm{R}^{2}$ & 0.9976 & 0.99 & 0.9946 & 0.9953 & 0.9977 & 0.9947 \\
& $\chi^{2}$ & 0.605 & 2.486 & 1.3747 & 0.9874 & 0.5719 & 1.6087 \\
& $\mathrm{RMSE}$ & 0.7778 & 1.5767 & 1.1725 & 0.9937 & 0.7562 & 1.2683 \\
\hline Difüzyon yaklaşım1ming & $\mathrm{R}^{2}$ & 0.9976 & 0.99 & 0.9946 & 0.9953 & 0.9977 & 0.9947 \\
Diffusion approach & $\chi^{2}$ & 0.605 & 2.486 & 1.3747 & 0.9874 & 0.5719 & 1.6087 \\
& $\mathrm{RMSE}$ & 0.7778 & 1.5767 & 1.1725 & 0.9937 & 0.7562 & 1.2683 \\
\hline B-B0'in kökü & $\mathrm{R}^{2}$ & 0.78 & 0.7899 & 0.7612 & 0.7099 & 0.7304 & 0.6767 \\
Root of B-B0 & $\chi^{2}$ & 45.6088 & 44.7391 & 50.6788 & 52.7933 & 56.0375 & 78.4657 \\
& $\mathrm{RMSE}$ & 6.7534 & 6.6887 & 7.1189 & 7.2659 & 7.4858 & 8.8581 \\
\hline Modifiye Page & $\mathrm{R}^{2}$ & 0.7637 & 0.77 & 0.747 & 0.6774 & 0.7062 & 0.658 \\
Modified Page & $\chi^{2}$ & 48.9789 & 48.9978 & 53.699 & 58.6967 & 61.0608 & 83.0046 \\
& $\mathrm{RMSE}$ & 6.9985 & 6.9998 & 7.328 & 7.6614 & 7.8141 & 9.1107 \\
\hline
\end{tabular}

Literatürde bitki çaylarının konsantrasyonunun modellendiği çalışmalara rastlanılamamıştır. Bununla birlikte benzer yöntemler ile meyve sularının konsantrasyonunun modellendiği sınırlı sayıda çalışmalar mevcuttur. Bu kapsamda Assawarachan ve Noomhorm (2011) ananas suyunun mikrodalga yöntem ile konsantrasyonunda deneysel verilere en uygun modelin modifiye Page olduğunu rapor etmiştir. Yousefi vd. (2012) nar suyunun mikrodalga ve geleneksel yöntem ile konsantrasyonunu tanımlamada birinci derece reaksiyon modelini kullandıklarını rapor ederken, Goula vd. (2014) nar suyunun termal yöntem ile konsantrasyonunda logaritmik modelin daha iyi sonuç verdiğini bildirmişlerdir. Diğer taraftan Dinçer vd. (2019) ve Sabancı ve Içier (2017) farklı yöntemler ile konsantre ettikleri meyve sularnnda, konsantrasyon karakteristiklerinin tanımlanmasında Midilli modelin en uyumlu model olduğunu rapor etmişlerdir.

Çizelge 3'te en uyumlu modeller olarak belirlenen Modifiye Henderson ve Pabis ile Midilli modellerine ait kinetik parametreleri sunulmuştur. Termal yöntem ile konsantre edilen adaçayı örneklerinde Modifiye Henderson ve Pabis modeli için hesaplanan $\mathrm{k}$ değerinin -0.2287 ile -
0.0729 arasında olduğu belirlenirken, mikrodalga yöntem ile konsantre edilen örneklerde Midilli model için hesaplanan $\mathrm{k}$ değeri ise $-6.7307 .10^{-6}$ ile -0.0003 arasında belirlenmiștir (Çizelge 3).

\section{Fizikokimyasal özellikler}

Sivı gidaların iletkenliğinin vitaminler, mineraller, yağ asitleri ve proteinler gibi besin maddelerinden kaynaklandığ1 ifade edilmekte (Aadil vd., 2013) ayrıca, iletkenliğin, ohmik 1sıtma, ultrason, darbeli elektrik alanları, radyo frekansli 1sitma veya mikrodalga 1sıtma ile işlenmesi için önemli olduğu bildirilmektedir (Siguemoto ve Gut, 2016). Bununla birlikte Çizelge 4 . incelendiğinde örneklerin iletkenlik değerlerinin 1518 ile 1723 $\mu \mathrm{s} / \mathrm{cm}$ arasında tespit edildiği, konsantrasyon işleminin örneklerin iletkenlik değerlerinde önemli bir değişime neden olmadığ görülmektedir. Konsantrasyon işlemlerinin adaçayı ekstraktlarının $\mathrm{pH}$ değerlerinde ise istatistiki açıdan önemli seviyede azalmaya neden olduğu ancak konsantrasyon yöntemleri arasında önemli bir fark olmadığı belirlenmiştir. Nitekim Onsekizoğlu (2013)'da nar suyu ile gerçekleştirdiği çalışmada $\mathrm{pH}$ ve titrasyon asitliği değerlerinde konsantrasyon yöntemine göre (termal ve membran konsantrasyon yöntemleri) önemli değişiklikler olmadığını rapor etmektedir. 
Çizelge 3. Farklı yöntemler ile konsantre edilmiş adaçayı ekstraktları için Midilli ve Henderson ve

Pabis modellerinin kinetik parametreleri.

Table 3. Kinetic parameters of Midilli and Henderson and Pabis models for sage extracts concentrated by various techniques.

\begin{tabular}{llcccc}
\hline $\begin{array}{l}\text { Matematiksel Model } \\
\text { Mathematical Model }\end{array}$ & $\begin{array}{l}\text { Konsantrasyon } \\
\text { metodu } \\
\text { Concentration method }\end{array}$ & \multicolumn{3}{c}{$\begin{array}{c}\text { Model sabitleri } \\
\text { Model constants }\end{array}$} \\
& & $\mathrm{a}$ & $\mathrm{k}$ & $\mathrm{n}$ & $\mathrm{b}$ \\
\cline { 2 - 5 } Henderson ve Pabis & T 75 & 0.0017 & -0.0729 & & \\
Henderson and Pabis & T 80 & $4.4859 .10^{-5}$ & -0.1883 & & \\
& T 85 & 0.0004 & -0.2287 & & \\
& MW 180 & $8.6647 .10^{-5}$ & -0.0831 & & \\
& MW 300 & 0.0002 & -0.1733 & & \\
\hline Midilli & MW 450 & $1.3587 .10^{-7}$ & -0.4806 & & \\
& T 75 & 0.1058 & -0.0004 & 1.9263 & 0.0045 \\
& T 80 & 0.1696 & $-3.5871 .10^{-6}$ & 3.3200 & 0.0261 \\
& T 85 & 0.1136 & -0.0005 & 2.3901 & 0.0302 \\
& MW 180 & 0.1177 & $-6.7307 .10^{-6}$ & 2.7035 & 0.0059 \\
& MW 300 & 0.0902 & -0.0003 & 2.3261 & 0.0074 \\
& MW 450 & 0.0749 & $-4.7926 .10^{-6}$ & 3.8025 & 0.0347 \\
\hline
\end{tabular}

Çizelge 4. Adaçayı örneklerinin bazı fizikokimyasal özellikleri Table 4. Physicochemical analysis results of sage samples

\begin{tabular}{|c|c|c|c|c|c|c|c|}
\hline & $\begin{array}{c}\text { Kontrol } \\
\text { Control }\end{array}$ & Т 75 & Т 80 & Т 85 & MW 180 & MW 300 & MW 450 \\
\hline $\mathrm{pH}$ & $5.76 \pm a 0.02$ & $5.66 \pm \mathrm{b} 0.02$ & $5.66 \pm \mathrm{b} 0.00$ & $5.69 \pm \mathrm{b} 0.01$ & $5.67 \pm \mathrm{b} 0.03$ & $5.68 \pm \mathrm{b} 0.01$ & $5.70 \pm \mathrm{b} 0.02$ \\
\hline $\begin{array}{l}\text { İletkenlik } \\
\text { ( } \mu \mathrm{s} / \mathrm{cm} \text { ) } \\
\text { Conductivity }\end{array}$ & $1528 \pm 56$ & $1648 \pm 15$ & $1628 \pm 5$ & $1518 \pm 179$ & $1687 \pm 102$ & $1608 \pm 79$ & $1723 \pm 17$ \\
\hline $\mathrm{L}^{*}$ & $18.36 \pm 0.10$ & $17.72 \pm 0.55$ & $18.15 \pm 0.06$ & $18.23 \pm 0.13$ & $18.02 \pm 0.02$ & $17.96 \pm 0.05$ & $18.07 \pm 0.03$ \\
\hline$a^{*}$ & $1.88 \pm 0.08$ & $2.06 \pm 0.15$ & $1.98 \pm 0.14$ & $1.97 \pm 0.05$ & $1.55 \pm 0.10$ & $1.65 \pm 0.07$ & $1.65 \pm 0.15$ \\
\hline $\mathrm{b}^{*}$ & $1.92^{\mathrm{ab} \pm 0.16}$ & $2.04 \pm a 0.02$ & $1.81 \pm \mathrm{abc} 0.11$ & $1.94 \pm \mathrm{ab} 0.19$ & $1.52 \pm \mathrm{c} 0.04$ & $1.52 \pm \mathrm{c} 0.07$ & $1.62 \pm \mathrm{bc} 0.05$ \\
\hline $\mathrm{C}$ & $2.68 \pm \mathrm{abc} 0.17$ & $2.92 \pm \mathrm{a} 0.14$ & $2.68 \pm \mathrm{abc} 0.17$ & $2.76 \pm \pm \mathrm{ab} 0.16$ & $2.17 \pm \mathrm{d} 0.09$ & $2.24 \pm \operatorname{cd} 0.10$ & $2.31 \pm \operatorname{bcd} 0.07$ \\
\hline $\mathrm{h}$ & $45.44 \pm 1.14$ & $45.07 \pm 1.63$ & $42.51 \pm 0.31$ & $44.51 \pm 2.16$ & $44.39 \pm 1.18$ & $42.62 \pm 0.12$ & $44.56 \pm 3.43$ \\
\hline NTU & $78.2 \pm \mathrm{b} 4.2$ & $56.3 \pm \mathrm{c} 0.2$ & $66.7 \pm$ bc1.1 & $69.8 \pm$ bc5.0 & $103.6 \pm$ a 8.5 & $78.3 \pm \mathrm{b} 7.8$ & $75.4 \pm$ b3.3 \\
\hline $\begin{array}{l}\text { TFM } \\
(\mathrm{mg} / \mathrm{L}) \\
\text { TPM }\end{array}$ & $3.73 \pm 0.03$ & $3.54 \pm 0.10$ & $3.55 \pm 0.15$ & $3.62 \pm 0.04$ & $3.67 \pm 0.02$ & $3.66 \pm 0.04$ & $3.66 \pm 0.01$ \\
\hline
\end{tabular}

T $75, \mathrm{~T} 80$ ve T $85: 75^{\circ} \mathrm{C}, 80^{\circ} \mathrm{C}$ ve $85^{\circ} \mathrm{C}$ deki termal vakum konsantrasyon. MW 180, MW 300 ve MW $450: 180 \mathrm{~W}, 300 \mathrm{~W}$ ve $450 \mathrm{~W}$ mikrodalga vakum konsantrasyon. Aynı satırdaki farklı harfler örnekler arası farkın istatistiksel olarak önemli

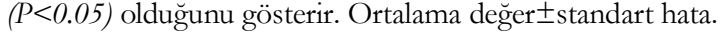

T 75, T 80 and T 85: Thermal vacuum concentration at $75^{\circ} \mathrm{C}, 80^{\circ} \mathrm{C}$ and $85^{\circ} \mathrm{C} . M W 180, M W 300$ and $M W$ 450: Microwave vacuum concentration at $M W 180, M W 300$ and $M W 450$. Different letters on the same line represent that the difference between the samples is statistically significant $(P<0.05)$. Mean values \pm standard error

Örneklerin $\mathrm{L}^{*}, \mathrm{a}^{*}$ ve $\mathrm{h}$ açısı renk değerlerinin uygulanan konsantrasyon yöntemlerine göre önemli bir değişim göstermediği belirlenirken $\mathrm{b}^{*}$ ve C (Chroma) değerinin istatistiki açıdan önemli seviyede değişim gösterdiği belirlenmiştir. Bununla birlikte $\mathrm{b}^{*}$ ve $\mathrm{C}$ renk değerlerindeki bu değişimin kontrol örneğine kıyasla artış ya da azalış seklinde net bir eğilim göstermediği görülmektedir. Benzer şekilde örneklerin bulanıklık (NTU) değerlerinde de istatistiki açıdan önemli seviyede bir değişim belirlenirken, bu değişim artış ya da azalış şeklinde net bir eğilim göstermemiştir. Diğer taraftan Bozkir ve Baysal (2016) mikrodalga vakum evaporasyon (668 W, 
$\left.500 \mathrm{mbar}, 82^{\circ} \mathrm{C}\right)$, rotary evaporasyon $(500 \mathrm{mbar}$, $82{ }^{\circ} \mathrm{C}$ ) ve yükselen film evaporator (500 mbar, 82 $\left.{ }^{\circ} \mathrm{C}\right)$ olmak üzere üç farklı yöntem ile konsantre ettikleri elma sularının $L^{*}$ ve $b^{*}$ renk değerlerinin kontrol örneğine göre daha düşük bulunduğunu rapor etmişlerdir. Aynı çalışmada mikrodalga vakum evaporasyon ve rotary evaporasyon ile konsantre edilen örneklerin $a^{*}$ değeri azalırken, yükselen film evaporator ile konsantre edilen örneklerin $\quad \mathrm{a}^{*}$ değerinin $\% \quad 4.69$ arttığ1 bildirilmiştir. Karadut suyu ile gerçekleştirilen başka bir çalısmada ise ozmotik distilayon ve termal evaporasyon (250 mbar, $\left.80{ }^{\circ} \mathrm{C}\right)$ ile konsantre edilen örneklerin $\mathrm{L}$ ve a değerlerinde önemli bir değişim bildirilmezken, b değerinin arttı̆̆1 rapor edilmiştir (Dinçer vd., 2016).

Biyoaktif maddelerce oldukça zengin olduğu ifade edilen adaçayı ekstraktlarında fenolik madde içeriği 3.54 ile $3.73 \mathrm{mg} / \mathrm{L}$ arasında tespit edilmiştir. Bununla birlikte uygulanan konsantrasyon işlemlerinin ekstraktlanın fenolik içeriğinde önemli bir değişime neden olmadığ 1 belirlenmiştir. Bu fenolik madde sonuçları göz önüne alındığında; adaçayı ekstraktlarının içerdiği fenolik bileşenlerin genel olarak uygulanan 75-85 ${ }^{\circ} \mathrm{C}$ 'deki termal vakum konsantrasyon ve $180-450$ W mikrodalga vakum konsantrasyon şartlarına karşı dayanıklı olduğu değerlendirilebilir. Nitekim adaçayı fenoliklerinin, ekstraksiyon (Torun vd., 2015) ve püskürterek kurutma (Şahin-Nadeem vd., 2013) gibi farklı sicaklıklarda $\left(60-80{ }^{\circ} \mathrm{C}\right.$ ve $145-165^{\circ} \mathrm{C}$ ) gerçekleştirilen proses şartlarında da önemli bir değişime uğramadığ 1 rapor edilmektedir. Adaçayı ekstraktlarının ters $\mathrm{Ozmoz}$ ve ardından ozmotik distilasyon yöntemi ile konsantre edildiği başka bir çalışmada ise ters ozmoz işleminin toplam fenolik madde içeriğinde önemli düzeyde azalmaya neden olduğu bununla birlikte ozmotik distilasyon yöntemi ile konsantre edilen adaçayı ekstraktlarında toplam fenolik bileşen analizinde geri kazanım oranının $\% 95$ gibi oldukça yüksek bir seyir izlediği bildirilmektedir (Torun vd., 2014).

\section{SONUÇ}

$\mathrm{Bu}$ çalışmada adaçayı ekstraktları $\left(1.4^{\circ} \mathrm{Bx}\right) 40$ ${ }^{\circ} \mathrm{Bx}$ 'e kadar termal ve mikrodalga yöntemleriyle başarıyla konsantre edilmiştir. Konsantrasyon süresi, mikrodalga gücü (180W'dan 450W'a) ve sıcaklık $\left(75^{\circ} \mathrm{C}\right.$ 'den $85^{\circ} \mathrm{C}$ ye) artışıly azaltılmıştır. Adaçayı ekstraktlarının konsantrasyonun modellenmesinde 13 farklı matematiksel model kullanılmıştır. Termal yöntemle konsantre edilen örneklerde en iyi uyumu Modifiye Henderson ve Pabis modeli sergilerken, mikrodalga yöntemiyle konsantre edilen örnekler için en iyi uyum gösteren model Midilli olarak belirlenmiştir. Konsantrasyon işlemleri adaçayı ekstraktlarının fizikokimyasal özelliklerinde genel olarak önemli değişimlere neden olmamıştır. Özellikle fenolik bileşenlerin konsantrasyon şartlannda önemli bir değişim göstermediği belirlenmiştir.

\section{ÇIKAR ÇATIŞMASI BEYANI}

Yazar, bu makalenin araşturilması, yazarlığı ve/veya yayınlanması ile ilgili potansiyel çıkar çatışması olmadığını beyan eder.

\section{KAYNAKLAR}

Aadil, R. M., Zeng, X. A., Han, Z., Sun, D. W. (2013). Effects of ultrasound treatments on quality of grapefruit juice. Food Chem. 141(3), 3201-3206.

https://doi.org/10.1016/j.foodchem.2013.06.00 8

Arslan, N., Yılmaz, G., Akınerdem, F., Özgüven, M., Kırıc1, S., Arıoğlu, H., Gümüşçü, A. Telci, İ. (2000). Nişasta-Şeker, tütün ve tıbbi-aromatik bitkilerin tüketim projeksiyonları ve üretim hedefleri. Türkiye Ziraat Mühendisliği V. Teknik Kongresi,. 1. Cilt, 453-483 ss, 17-21 Ocak, Ankara.

Assawarachan, R., Noomhorm, A. (2011). Mathematical models for vacuum-microwave concentration behavior of pineapple juice. J. Food Process Eng. 34(5), 1485-1505. https://doi.org/10.1111/j.17454530.2009.00536.x

Baser, K. H. C. (2002). Aromatic biodiversity among the flowering plant taxa of Turkey. Pure Appl. Chem. 74(4), 527-545. ttps://doi.org/10.1351/pac200274040527

Baydar, H. (2005). Tibbi, Aromatik ve Keyf Bitkileri Bilimi ve Teknolojisi. Süleyman Demirel Üniversitesi 51, 216 ss, Isparta. 
Bozkir, H., Baysal, T. (2017). Concentration of apple juice using a vacuum microwave evaporator as a novel technique: Determination of quality characteristics. J. Food Process Eng. 40(5), e12535. https://doi.org/10.1111/jfpe.12535

Chandrasekaran, S., Ramanathan, S., Basak, T. (2013). Microwave food processing-A review. Food Res. Int. 52(1), 243-261. https://doi.org/10.1016/j.foodres.2013.02.033.

Davis, P. H. (1982). Flora of Turkey and the East Aegean Islands, Vol. 3. Edinburg University Press, Vol.7, 947 ss, Edinburg.

Delamare, A. P. L., Moschen-Pistorello, I. T., Artico, L., Atti-Serafini, L., Echeverrigaray, S. (2007). Antibacterial activity of the essential oils of Salvia officinalis L. and Salvia triloba L. cultivated in South Brazil. Food Chem. 100(2), 603608.

https://doi.org/10.1016/j.foodchem.2005.09.07 8

Delgado, T., Pereira, J. A., Baptista, P., Casal, S., Ramalhosa, E. (2014). Shell's influence on drying kinetics, color and volumetric shrinkage of Castanea sativa Mill. fruits Food Res. Int. 55, 426435. doi:10.1016/j.foodres.2013.11.043

Dinçer, C., Çam, İ. B., Torun, M., Gülmez, H. B., Topuz, A. (2019). Mathematical modeling of concentrations of grape, pomegranate and black carrot juices by various methods. Gida, 44(6), 1092-1105.

https://doi.org/10.15237/gida.GD19080

Dincer, C., Tontul, I., Topuz, A. (2016). A comparative study of black mulberry juice concentrates by thermal evaporation and osmotic distillation as influenced by storage. Innovative Food Sci. Emerg. Technol. 38, 57-64. https://doi.org/10.1016/j.ifset.2016.09.012

El-Sayed, N. H., Khalifa, T. I., Ibrahim, M. T., Mabry, T. J. (2001). Constituents from Salvia triloba. Fitoterapia, 72(7), 850-853. https://doi.org/10.1016/S0367-326X(01)003276

Gezek, G., Hashemi, P., Kalaycioğlu, Z., Kaygusuz, H., Sarığlu, G., Döker, S., ... Erim, F. B. (2019). Evaluation of some Turkish Salvia species by principal component analysis based on their vitamin B2, mineral composition, and antioxidant properties. LWT Food Sci. Technol.100, 287-293.

https://doi.org/10.1016/j.lwt.2018.10.066

Goula, A. M., Tzika, A., Adamopoulos, K. G. (2014). Kinetic models of evaporation and total phenolics degradation during pomegranate juice concentration. Int. J. Food Eng. 10(3), 383-392. https://doi.org/10.1515/ijfe-2014-0016

Kumar, C., Joardder, M. U. H., Farrell, T. W., Millar, G. J.,Karim, M. A. (2016). Mathematical model for intermittent microwave convective drying of food materials. Drying Technol. 34(8), 962-973.

https://doi.org/10.1080/07373937.2015.108740 8

Midilli, A., Kucuk, H., Yapar, Z. (2002). A new model for single-layer drying. Drying Technol. 20(7), https://doi.org/10.1081/DRT-120005864. 1503-1513.

Onsekizoglu, P. (2013). Production of high quality clarified pomegranate juice concentrate by membrane processes. J. Membr. Sci. 442, 264-271. https://doi.org/10.1016/j.memsci.2013.03.061

Sabanci, S., Icier, F. (2017). Applicability of ohmic heating assisted vacuum evaporation for concentration of sour cherry juice. J. Food Eng. 212,

262-270. https://doi.org/10.1016/j.jfoodeng.2017.06.004

Siguemoto, É. S., Gut, J. A. W. (2016). Dielectric properties of cloudy apple juices relevant to microwave pasteurization. Food Bioprocess Technol. $9(8)$, 1345-1357. https://doi.org/10.1007/s11947-016-1723-0

Škerget, M., Kotnik, P., Hadolin, M., Hraš, A. R., Simonič, M., Knez, Ž. (2005). Phenols, proanthocyanidins, flavones and flavonols in some plant materials and their antioxidant activities. Food Chem. 89(2), 191-198. https://doi.org/10.1016/j.foodchem.2004.02.02 5

Swain, S., Samuel, D. V. K., Bal, L. M., Kar, A., Sahoo, G. P. (2012). Modeling of microwave assisted drying of osmotically pretreated red sweet 
pepper (Capsicum annum L.). Food Sci. Biotechnol. 21(4), 969-978. https://doi.org/10.1007/s10068012-0127-9

Şahin-Nadeem, H., Dinçer, C., Torun, M., Topuz, A., \& Özdemir, F. (2013). Influence of inlet air temperature and carrier material on the production of instant soluble sage (Salvia fruticosa Miller) by spray drying. LWT Food Sci. Technol. 52(1), 31-38. https://doi.org/10.1016/j.lwt.2013.01.007

Tajchakavit, S., Boye, J. I., Bélanger, D., Couture, R. (2001). Kinetics of haze formation and factors influencing the development of haze in clarified apple juice. Food Res. Int. 34(5), 431-440. https://doi.org/10.1016/S0963-9969(00)001885

Tepe, B. (2002). Lamiaceae familyasina ait baz1 bitki türlerinin antimikrobiyal aktivitelerinin araşturılması. Cumhuriyet Üniversitesi Fen Bilimleri Enstitüsü, (Yüksek Lisans Tezi) 66 ss, Sivas.

Tontul, I., Topuz, A. (2017). Spray-drying of fruit and vegetable juices: Effect of drying conditions on the product yield and physical properties. Trends Food Sci. Technol. 63, 91-102. https://doi.org/10.1016/j.tifs.2017.03.009

Torun, M., Rácz, G., Fogarassy, E., Vatai, G., Dinçer, C., Topuz, A., Özdemir, F. (2014). Concentration of sage (Salvia fruticosa Miller) extract by using integrated membrane process. Sep. Purif. Technol. 132, 244-251. https://doi.org/10.1016/j.seppur.2014.05.039

Torun, M., Dincer, C., Topuz, A., Sahin-Nadeem, H., Ozdemir, F. (2015). Aqueous extraction kinetics of soluble solids, phenolics and flavonoids from sage (Salvia fruticosa Miller) leaves. J. Food Sci. Technol. 52(5), 2797-2805. https://doi.org/10.1007/s13197-014-1308-8

Tunalıer, Z., Öztürek, N., Koşar. M., Başer, K.H.C., Duman, H. ve Kırımer, N. 2002. Baz1 Sideritis türlerinin antioksidan etki ve fenolik bileşikler yönünden incelenmesi. Bitkisel ilaç hammaddeleri toplantıs1, bildiriler, 29-31 Mayıs, Eskişehir.

Vadivambal, R., Jayas, D. S. (2007). Changes in quality of microwave-treated agricultural products—a review. Biosyst. Eng. 98(1), 1-16. https://doi.org/10.1016/j.biosystemseng.2007.0 6.006

Vega-Gálvez, A., Puente-Díaz, L., LemusMondaca, R., Miranda, M., \& Torres, M. J. (2014). Mathematical Modeling of Thin-Layer Drying Kinetics of Cape Gooseberry (Physalis peruviana L.). J. Food Process. Preserv. 38(2), 728-736. Doi: $10.1111 /$ jfpp.12024

Yağcioğlu, P. (2015). Farklı Ekstraksiyon Metotları ile Adaçayı (Salvia Officinalis L.) Bitkisinden Antioksidan Ekstraksiyonunun Optimizasyonu. İstanbul Teknik Üniversitesi Fen Bilimleri Enstitüsü Gıda Mühendisliği Anabilim Dalı Yüksek Lisans Tezi, İstanbul, Türkiye, $95 \mathrm{~s}$.

Yousefi, S., Emam-Djomeh, Z., Mousavi, S. M. A., Askari, G. R. (2012). Comparing the effects of microwave and conventional heating methods on the evaporation rate and quality attributes of pomegranate (Punica granatum L.) juice concentrate. Food Bioprocess Technol. 5(4), 13281339. http://doi.org/10.1007/s11947-011-0603$\mathrm{X}$ 